\title{
KIT NM_000222.2:c.2464A>T
}

National Cancer Institute

\section{Source}

National Cancer Institute. KIT NM 000222.2:C.2464A>T. NCI Thesaurus. Code C155707.

A nucleotide substitution at position 2464 of the coding sequence of the KIT gene where adenine has been mutated to thymine. 